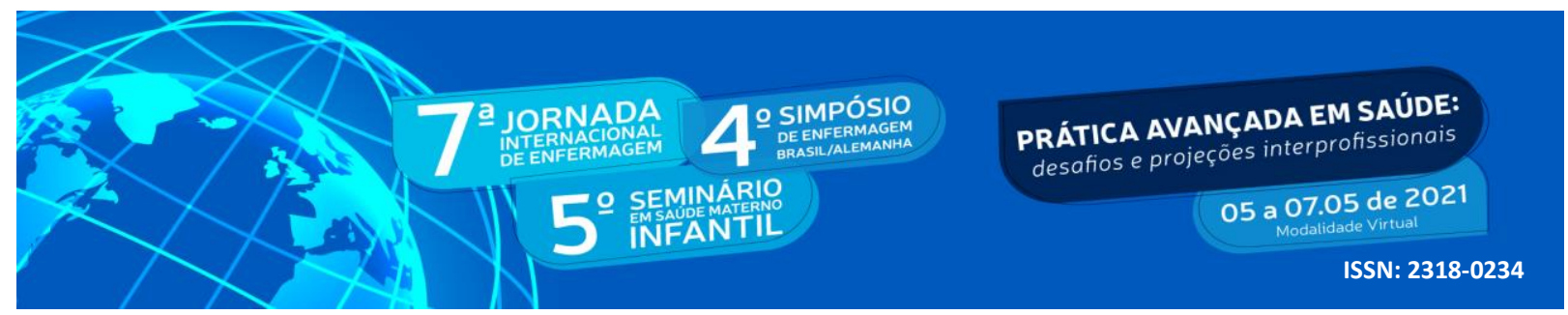

DOI: http://doi.org/10.48195/jie2021-049

\title{
PERCEPÇÃO DE ESTUDANTES DA SAÚDE ACERCA DAS BOAS PRÁTICAS DE ATENÇÃO AO PARTO E NASCIMENTO ${ }^{1}$
}

\section{Giovana Luiza Rossato² ${ }^{2}$ Leandro da Silva de Medeiros ${ }^{3}$; Eduarda Rodrigues Machado ${ }^{4}$; Victória Friedrich Costa $^{5}$; Camila Cioquetta Pereira ${ }^{6}$; Dirce Stein Backes ${ }^{7}$ \\ RESUMO}

Objetivo: Conhecer a percepção de estudantes da saúde acerca das boas práticas de atenção ao parto e nascimento. Método: Trata-se de uma pesquisa exploratória descritiva com abordagem qualitativa, realizada no período de janeiro a março de 2021. Participaram do estudo 12 estudantes da área da saúde, por meio de entrevistas com questões norteadoras, realizadas pela plataforma remota "ZOOM". Os dados coletados foram analisados com base na técnica de análise de conteúdo preconizada por Minayo. Resultados: Emergiram duas categorias temáticas: As contribuições dos profissionais de saúde e Boas práticas de atenção e seus sentidos. Conclusão: $\mathrm{O}$ estudo possibilitou perceber que os acadêmicos da área da saúde, a partir de suas vivências, compreendem a necessidade de ter profissionais humanizados, em especial, profissionais da enfermagem para desenvolver boas práticas ao parto e nascimento nos diversos âmbitos da saúde. Bem como, repensar sobre a atenção obstétrica, proporcionando o protagonismo da mulher.

Palavras-chave: Equipe de Assistência ao paciente; Humanização de Assistência ao Parto; Pesquisa Qualitativa; Saúde Materno-Infantil.

\section{ABSTRACT}

Objective: To know the perception of health students about good practices of childbirth and birth care. Method: This is a descriptive exploratory research with a qualitative approach, carried out from January to March 2021. The study included 12 health students, through interviews with northern questions, conducted by the remote platform "ZOOM". The collected data were analyzed based on the

\footnotetext{
${ }^{1}$ Trabalho de pesquisa realizado com apoio do Programa Institucional de Bolsas de Iniciação Científica (PROBIC/UFN).

${ }^{2}$ Estudante do Curso de Enfermagem - Universidade Franciscana (UFN). Bolsista de Iniciação Científica. Email: rossatogiovana@gmail.com

${ }^{3}$ Estudante do Curso de Enfermagem - Universidade Franciscana (UFN). Bolsista voluntário de IC.E-mail : leandro.medeiros@ufn.edu.br

${ }^{4}$ Estudante do Curso de Enfermagem - Universidade Franciscana (UFN). Bolsista voluntária de IC. E-mail: eduardamachado886@gmail.com

${ }^{5}$ Estudante do Curso de Enfermagem - Universidade Franciscana (UFN). Bolsista voluntária de IC. E-mail: victoriafriedrich27@gmail.com

${ }^{6}$ Estudante do Curso de Enfermagem - Universidade Franciscana (UFN). Bolsista voluntária de IC. E-mail: camicioquetta@gmail.com

7 Orientadora. Doutora em Enfermagem. Docente do Curso de Enfermagem e Coordenadora do Mestrado Profissional Saúde Materno Infantil - Universidade Franciscana. E-mail: backesdirce@ufn.edu.br
} 


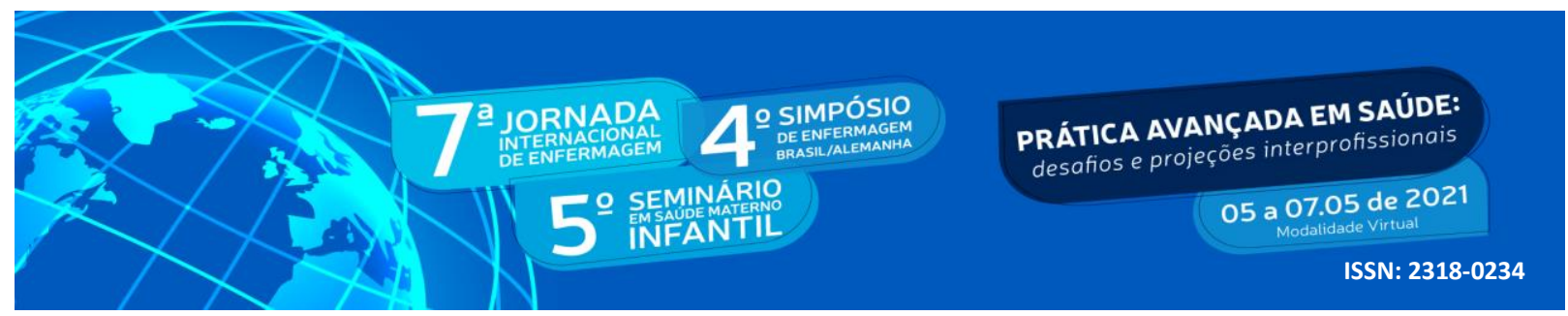

content analysis technique recommended by Minayo. Results: Two thematic categories emerged: The contributions of health professionals and good care practices and their senses. Conclusion: The study made it possible to realize that health students, based on their experiences, understand the need to have humanized professionals, especially nursing professionals to develop good practices at birth in the various health areas. As well as, rethink about obstetric care, providing the leading role of women.

Key Words: Patient Care Team; Humanization of Childbirth Assistance; Qualitative Research; Maternal and Child Health.

\section{INTRODUÇÃO}

As boas práticas de atenção ao parto e nascimento foram descritas, inicialmente, em 1996, pela Organização Mundial de Saúde (OMS) e, atualizadas, em 2018. Essas são práticas comuns determinadas para a condução do processo de parturição, baseadas em evidências científicas, com a finalidade de estabelecer cuidados adequados e seguros para a mulher e assegurar a qualidade da assistência materno-infantil (WHO, 2018).

A busca pela qualidade da atenção em saúde materno-infantil é uma temática recorrente e discutida nos diferentes espaços e contextos da saúde. Dentre as diversas condutas e prospecções, destaca-se a Rede Cegonha, instituída no Sistema Único de Saúde (SUS), no ano de 2011. Esta dispõe de prerrogativas que asseguram o direito da mulher para ter um planejamento reprodutivo e atenção humanizada durante o pré-natal, parto e puerpério, além de cuidados efetivos às crianças, do nascimento seguro ao crescimento e desenvolvimento saudável (BRASIL, 2011).

O programa Rede Cegonha permitiu avanços significativos na área da saúde maternoinfantil. Atualmente, o Brasil conta com 270 serviços hospitalares aptos para o atendimento, divididos em 198 unidades de Gestação de Alto Risco (GAR), 32 unidades de Casa de Gestante, Bebê e Puérpera (CGBP) e 40 unidades de Centro de Parto Normal (CPN) (BRASIL, 2020). Tais serviços visam fomentar cuidados humanizados na atenção ao parto e nascimento, a partir de espaços acolhedores, acessíveis e resolutivos (BRASIL, 2011).

Qualificar a assistência materno-infantil é fator premente para prospectar o desenvolvimento humano e social de forma saudável e sustentável. Considerando a importância de observar cada pessoa dentro de suas especificidades e trabalhar a partir dessas, percebe-se que intervenções humanizadas que considerem o binômio mãe-bebê são cada vez 


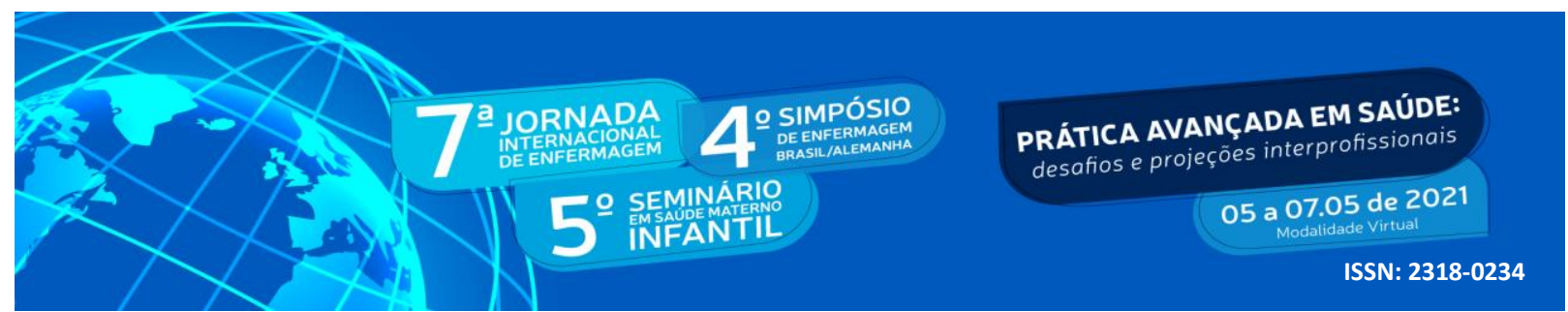

mais estimuladas. Além disso, o comprometimento profissional no que se refere ao acolhimento com respeito e dignidade, bem como os cuidados resolutivos são cada vez mais reforçados (ARAÚJO et al., 2019).

Neste sentido, com base em novos referenciais e evidências científicas, foram classificadas as boas práticas para orientar as condutas dos profissionais. Consideradas como: práticas claramente úteis e que devem ser estimuladas; práticas claramente prejudiciais ou ineficazes e que devem ser eliminadas; e práticas usadas de modo inapropriado no momento de trabalho de parto e parto. Desse modo, no Brasil consta que as boas práticas durante o trabalho de parto acontecem em menos de 50\% das mulheres, demonstrando a premente necessidade de avançar na superação de modelos tradicionais (ROCHA et al., 2017).

Assim, de modo a entrelaçar os conhecimentos até então explanados, parte-se neste instante, para uma análise global. Para tanto, faz-se necessário destacar que dentre as metas dos Objetivos do Desenvolvimento Sustentável (ODS), definidas para o ano de 2030 é a redução de 70 mortes por 100.000 nascidos vivos e acabar com as mortes evitáveis de recémnascidos e crianças menores de 5 anos (OPAS, 2021). Esta meta somente será atingida por meio de esforços coletivos pautados em novos saberes e práticas, sustentadas em evidências científicas.

Dessa forma, impulsionar as boas práticas de atenção ao parto e nascimento preconizadas pela OMS, sobretudo, por inserir-se nos ODS e na Agenda de Prioridades de Pesquisa do Ministério da Saúde, mais especificamente no Eixo 14 - Saúde Materno Infantil (BRASIL, 2018), questiona-se: Qual a percepção de estudantes da área da saúde acerca das boas práticas de atenção ao parto e nascimento?

\section{OBJETIVO}

Conhecer a percepção de estudantes da saúde acerca das boas práticas de atenção ao parto e nascimento.

\section{METODOLOGIA}




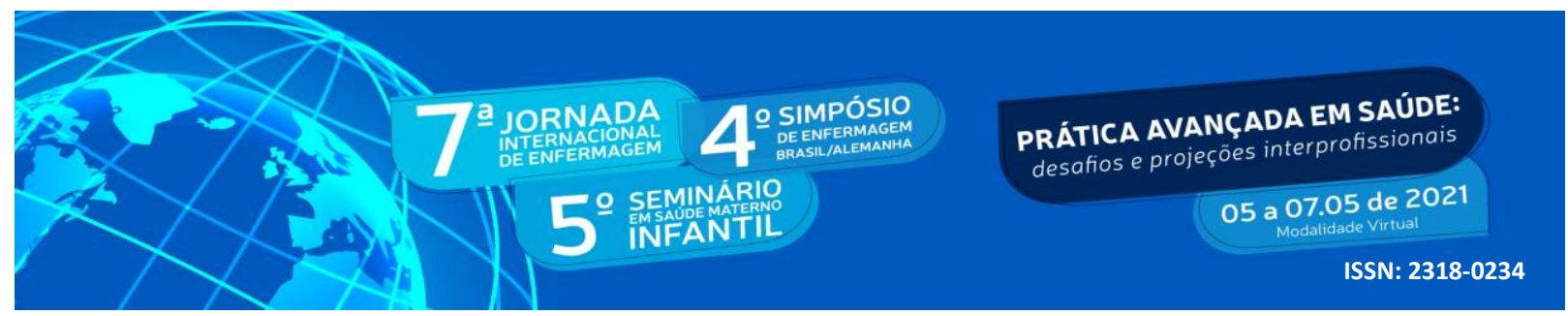

Realizou-se uma pesquisa qualitativa de caráter exploratória-descritiva. A pesquisa qualitativa se caracteriza "por meio de expressões e significados que as pessoas dão a suas experiências e vivências. Todos têm como parâmetro o reconhecimento da subjetividade, do simbólico e da intersubjetividade nas relações, e trazem para o interior das análises [...]"( MINAYO, 2017, p. 16).

Fizeram parte deste estudo 12 acadêmicos (as). Os critérios de inclusão foram: ter mais de 18 anos, ser participante dos eventos promovidos pelo grupo GESTAR, ser pesquisador ou acompanhante das postagens nas redes sociais Instagram e Facebook, sobre diversas temáticas relacionadas à saúde materno-infantil e aceitar participar da pesquisa.

Após o aceite, os entrevistados foram informados que sua participação seria voluntária e foram esclarecidos sobre os direitos da sua desistência em qualquer momento da pesquisa. $\mathrm{O}$ sigilo dos dados fornecidos foi assegurado e informado que os resultados do estudo seriam apresentados em eventos e publicados em revistas científicas. A identificação dos (as) participantes foi feita a partir das iniciais A ( acadêmicos) do número na ordem do texto ( $\mathrm{A} 1$, A2...).

A coleta de dados se deu no período de janeiro a março de 2021, por meio da plataforma remota (Zoom), mediante a técnica de entrevistas com questões norteadoras abertas de caráter qualitativo, sendo estas: “Quais estratégias você considera importante para o fomento de Boas Práticas em Saúde Materno-Infantil?” e “Qual a sua sugestão para ampliar o processo de discussão sobre as boas práticas obstétricas no GESTAR?", no sentido de possibilitar a interação entre pesquisadores e participantes. Favoreceu-se, dessa forma, a contextualização de experiências, vivências e perspectivas que contribuíram para esclarecer a problemática da investigação. Os dados coletados foram analisados com base na técnica de análise de conteúdo preconizada por Minayo ( 2017).

Todos os aspectos da Bioética foram respeitados na realização da pesquisa. $O$ consentimento na participação deu-se através dos registros nas gravações de vídeos ou aúdios, respaldado pelo o Ofício Circular No 2/2021/CONEP/SECNS/MSO de 24 de fevereiro de 2021. Entretanto, alguns Termos de Consentimento Livre e Esclarecido foram assinados pela 


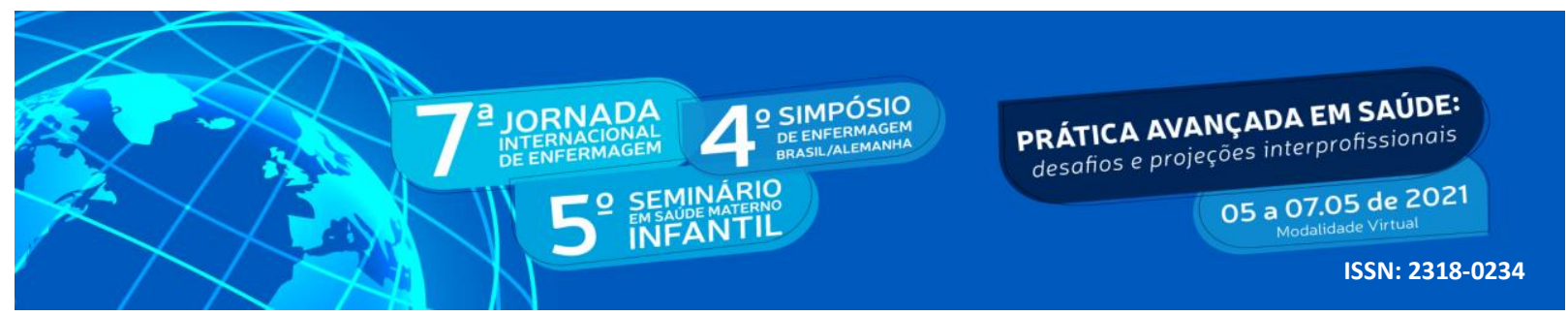

oportunidade de encontro com os participantes, respeitando as normas sanitárias da pandemia. Assim, o presente estudo tem parecer favorável do Comitê de Ética em Pesquisa (CEP) sob o número de protocolo: 4.253.922.

\section{RESULTADOS E DISCUSSÃO}

Da análise dos dados emergiram duas categorias temáticas: As contribuições dos profissionais de saúde e Boas práticas de atenção e seus sentidos, conforme segue:

\subsection{As contribuições dos profissionais de saúde}

Compreende-se o parto e o nascimento como um acontecimento marcante na vida das mulheres, sendo cada vez mais necessário englobar boas práticas que fomentem os avanços da obstetrícia. As evoluções permitiram melhores indicadores mundiais de morbidade e mortalidade materna e perinatal. A partir disso, é necessário oportunizar às mulheres partos que respeitem seus aspectos emocionais, culturais, humanos e com intervenções que sejam realmente essenciais para o processo (BRASIL, 2017). Conforme a fala que segue os estudantes tem a compressão que:

"Eu tive agora na maternidade, no meu estágio, e eu presenciei, eu tive a oportunidade de presenciar duas enfermeiras, Então tu vê a diferença que um enfermeiro faz na hora do trabalho de parto, a diferença que tem de um para o outro (...) de tu ter aquela parte humanizada, mas tu mostrar também os benefícios que tem, tu não impor alguma coisa pra aquela mãe." ( A1)

Em seus depoimentos os participantes salientam a importância da equipe multiprofissional, sobretudo, da enfermagem obstétrica. Demonstraram que as boas práticas de atenção ao parto transcendem o caráter biológico e que possam, dessa forma, alcançar a singularidade humana.

O parto, no decorrer dos anos, deixou de ser um momento privado para a gestante e sua família, pois muitas das pessoas que acompanham o processo são desconhecidas, estando ali apenas para olhar o recém-nascido e não para dar a atenção necessária à mãe. Dessa forma, o 


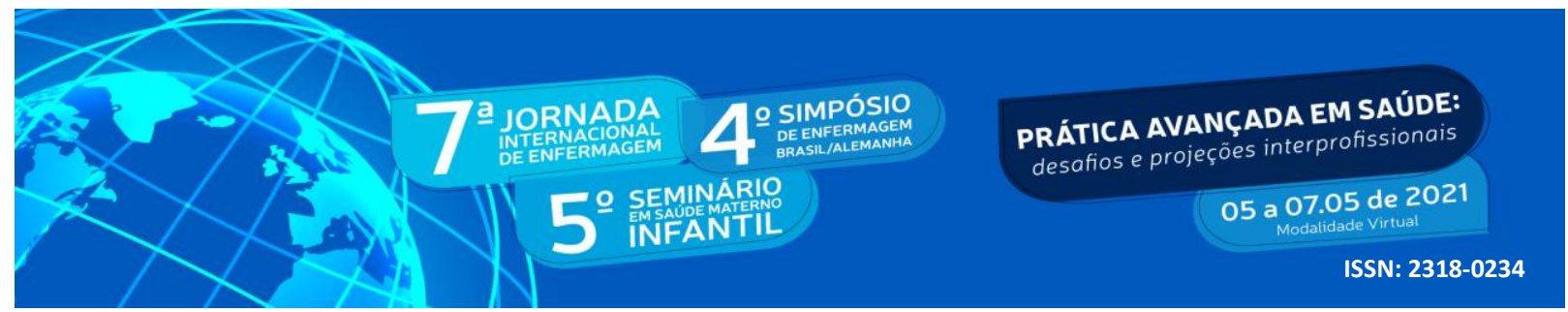

enfermeiro por ser o profissional do cuidado integrador, figura como sendo o profissional mais capacitado para acompanhar a mulher, tanto antes do nascimento quanto depois, acolhendo-a e criando vínculos (GOMES, 2017).

A Enfermeira obstétrica é uma especialização da área de enfermagem, no qual o profissional vai capacitar-se para prestar atendimento integral às mulheres grávidas, na hora do parto e no puerpério. Essa área da enfermagem tem contribuído para a segurança da mulher e seu recém-nascido, fornecendo conforto e auxílio na conduta de exercícios que irão ajudar durante e após o parto. A participação desse profissional pode garantir que o equilíbrio entre intervenções desnecessárias e o processo fisiológico do parto sejam adequadas evitando, assim, que as gestantes não passem por situações traumáticas sem motivos. (SANTOS et al, 2019). A

Em virtude disso, os profissionais de saúde que atendem às mulheres durante o período gravídico-puerperal são responsáveis por organizar atendimentos que, de fato, fortaleçam a autonomia e o protagonismo das mesmas. Constata-se a importância de trabalhar valores e desejos de acordo com cada mulher, respeitando a sua singularidade e permitindo que esse momento seja humanizado (NASCIMENTO et al, 2020). Assim, os profissionais em "suas próprias crenças e valores influenciam a sua atitude em lidar com a dor do parto e garantir que os seus cuidados apoiem a escolha da mulher.” (BRASIL, 2017, p.17). Nesse sentido, é perceptível como esses aspectos são necessários e merecem destaque em qualquer ambiente:

"Em primeiro lugar é tu transcender aquela parte técnica pontual sabe. É tu está, como que eu posso dizer (...) tu da a autonomia para aquele gestante, realizar todo o período da gravidez dela de uma forma autônoma, de uma forma que ela tenha o conhecimento, que tu como profissional, mostra pra ela todo conhecimento que tu tem, tirar as dúvidas, para que ela tenha todo o acompanhamento necessário, pra que na hora do parto ela tenha aquele parto humanizado, aquele parto como ela preferir parir, como ela deseja trazer o bebê, né” (A5).

\subsection{Boas práticas de atenção e seus sentidos}




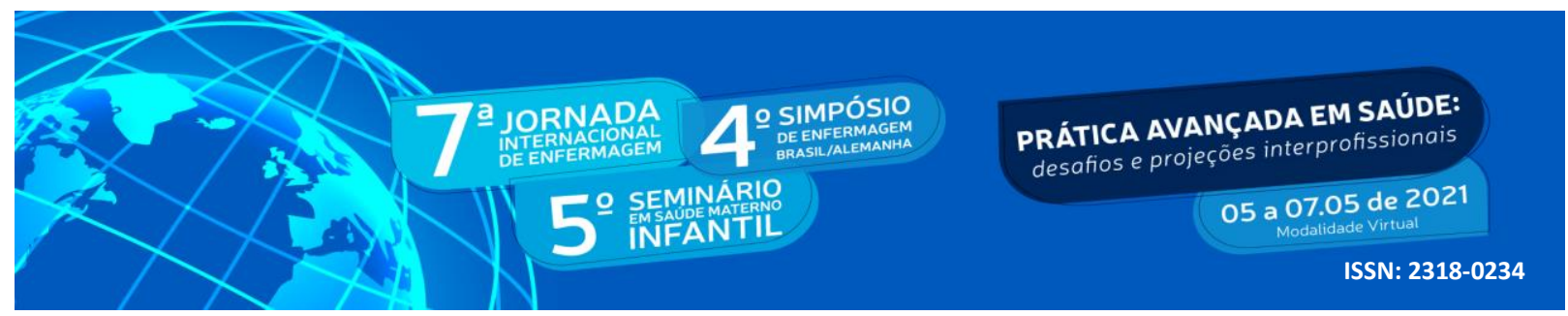

Outra perspectiva para compreender as boas práticas ao parto e nascimento estão relacionadas ao plano de parto. Este caracteriza-se como documento em que a gestante registra as suas vontades em relação ao parto e quais procedimentos não gostaria que fossem realizados, evitando situações constrangedoras e desnecessárias. É um instrumento que beneficia a gestante e o profissional responsável, pois terá esclarecida cada técnica que será realizada. Além disso, a gestante vai ter mais controle sobre o seu corpo e o nascimento do bebê ( SILVA et al, 2017). Com isso, a utilização do plano de parto é uma estratégia que integra e contempla os desejos singulares da gestante, consoante com a seguinte fala:

"O plano de parto né, que às vezes é muito pouco discutido no(...) na parte do(...) puerpério ali, pouco discutido, pouco lembrado às vezes mas(...) que é muito(...) legal né porque é um meio de tu ver o que a gestante quer(...) que ela espera de ta ali, pra ver também conversar com ela, pra ver quais são as melhores decisões, conversar em conjunto, claro sem botar em risco uma(...) o bebê nem a gestante, por alguma (...)o querer dela, digamos assim, mas sempre tentar(...) fazer o parto, o puerpério enfim(...) da maneira que ela imaginou” (A3)

No que se refere às estratégias que aliviam as dores durante o trabalho de parto sem a utilização de medicamentos, destacam-se "as massagens corporais, os banhos (de chuveiro ou imersão), as técnicas de respiração e o relaxamento, deambulação ativa, toques confortantes, utilização das bolas e cavalinhos, exercícios e outras medidas de suporte físico e emocional" (MELO et al, 2017, p.1). Estas atividades, no entanto, devem ser estimuladas e analisadas conforme a situação de cada gestante e realizadas assim que possível:

"Na área hospitalar é não só estimular que a mulher caminhe, porque durante a prática a gente vê: Ah, caminha pra estimular mais o parto. E só o caminhar não resolve, porque essa mãe, ela tá muito angustiada, ela tá muito ansiosa, pra esse primeiro momento que as vezes é, né, primeiro filho e tudo mais, então, não só caminhar mas estimular com boas práticas, nesse sentido né, então um banho, utilizar a bola, utilizar aromas." (A4)

O parto é um dos momentos mais aguardados e planejados pela gestante, pois será quando conhecerá seu filho. Por esse motivo, nas primeiras horas de vida do bebê é essencial que 


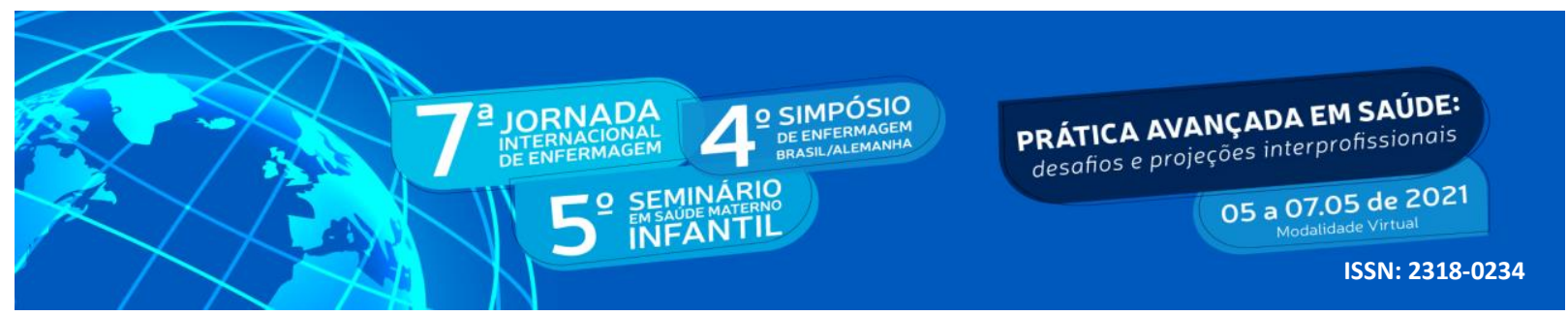

neste seja realizado o contato pele a pele para que auxilie na adaptação relacionada à mudança do local intra para o extrauterino, mas também incentivá-lo no processo de amamentação. As evidências científicas reforçam que essas ações devem ser cada vez mais praticadas, devido ao fato de demonstrarem resultados satisfatórios (SILVA et al, 2016). Percebeu-se na pesquisa, no entanto, que muitas vezes após o nascimento do bebê, transcorrem-se outras situações:

"Então eu tive várias oportunidades de(...) presenciar alguns partos e(...) eu(...) o que eu senti(...) foi que a gente dá muita atenção pra mãe até o bebê sair(...) depois que o bebê saiu, tá todo mundo em volta do bebê e fica a mãe ali deitada na cama sem entender muitas vezes o que aconteceu(...)” (A2)

Nesse seguimento, este depoimento abrange a percepção da mãe em vivenciar tal situação:

"Nossa! Agora que o bebê nasceu, todo mundo me esqueceu(...) isso doeu né(...) porque é uma realidade às vezes dos profissionais(...) porque realmente às vezes o bebê nasce e aí a puérpera fica ali descansando, só que ela fica às vezes sozinha, então eu fiquei lá conversando com ela, acalmando ” (A2)

Compreende-se que o apoio oferecido à mãe após o parto é fundamental, visto que, encontra-se em um estado de muita sensibilidade e mudanças fisiológicas. Frente a isso, o acompanhante mostra-se como ferramenta essencial e não invasiva, referenciado como uma pessoa muito positiva para amparar à mulher neste momento, deixando-a mais encorajada, confiante e tranquila (RIBEIRO et al, 2018). No entanto, muitas vezes, os profissionais devem atentar-se quanto os sinais e desfechos que possam acontecer a respeito disso:

"Outra parte também do acompanhante, do pai ou quem ela preferir que acompanhe na hora do parto, acho uma parte bem importante por conta que eu presenciei na maternidade. Uma menina que ela não queria que o pai participasse porquê ela se sentia constrangida, né, ela se sentiu constrangida, porque ela não queria, sei lá, evacuar, um exemplo, ela não queria que o acompanhante visse" (A5).

Os resultados deste estudo demonstram, em suma, que não bastam regulamentos, protocolos ou planos de parto relacionados às boas práticas obstétricas. Para, além disso, são 


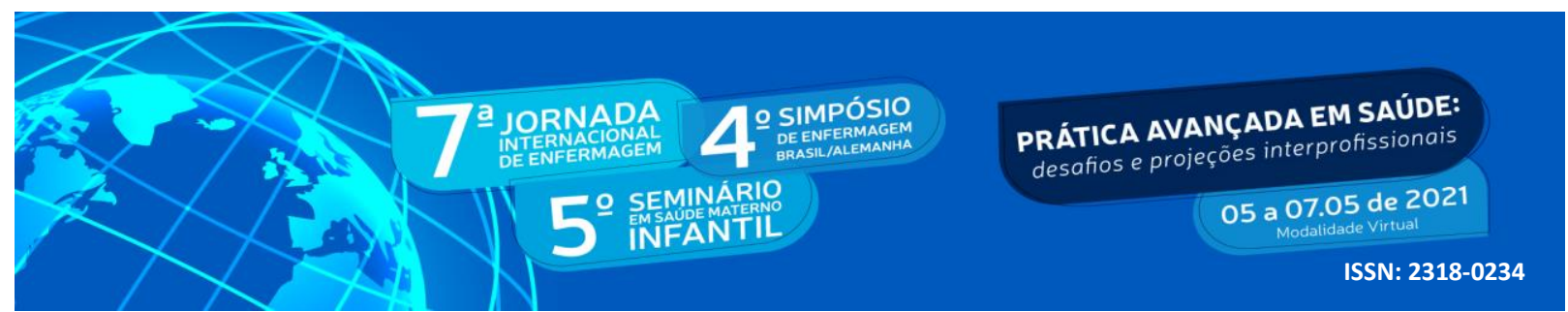

necessárias atitudes e posturas profissionais que contemplem as singularidades de cada gestante, a fim de possibilitar um parto acolhedor e seguro.

\section{CONCLUSÃO}

O estudo possibilitou perceber que os acadêmicos da área da saúde, a partir de suas vivências, compreendem a necessidade de ter profissionais humanizados, em especial, profissionais da enfermagem para desenvolver boas práticas ao parto e nascimento nos diversos âmbitos da saúde. Bem como, repensar sobre a atenção obstétrica, a fim de garantir o acesso, acolhimento, resolutividade e protagonismo da mulher em suas múltiplas dimensões.

Por essa razão, é preciso desmistificar crenças, superar práticas desnecessárias e transcender barreiras impostas pelo modelo hegemônico de intervenção obstétrica. Para isso, defende-se, a partir deste estudo, a ampliação de espaços de discussões em ambientes de ensino acerca da temática das boas práticas de atenção ao parto e nascimento. Aos profissionais de saúde, ações de educação permanente para que compreendam a necessidade de utilizar práticas, no qual respeitem a autonomia da gestante, escutem suas vontades, acolham as suas inseguranças, propiciando um parto conforme foi almejado pela mulher.

\section{REFERÊNCIAS}

ARAÚJO, I. C. F. G. et al. Qualidade do parto e impacto nos indicadores da saúde da criança. Revista Ciência Plural, v. 5, n. 1, p. 18-33, 5 jun. 2019.

BRASIL. Diretrizes nacionais de assistência ao parto normal: versão resumida [recurso eletrônico]. Ministério da Saúde, Secretaria de Ciência, Tecnologia e Insumos Estratégicos, Departamento de Gestão e Incorporação de Tecnologias em Saúde. - Brasília : Ministério da Saúde, 2017.

BRASIL. Ministério da Saúde. Gabinete do Ministro. Portaria n ${ }^{\circ} 1.459$, de 24 de Junho de 2011. Institui, no âmbito do Sistema Único de Saúde - SUS - a Rede Cegonha. Diário Oficial da União, Brasília, DF, 24 jun. 2011.

BRASIL. Ministério da Saúde. Ministério da Saúde reforça cuidados materno-infantis no SUS. Brasília, DF: MINISTÉRIO DA SAÚDE, 2020. Disponível em: https://antigo.saude.gov.br/noticias/agencia-saude/47620-ministerio-da-saude-reforca- 


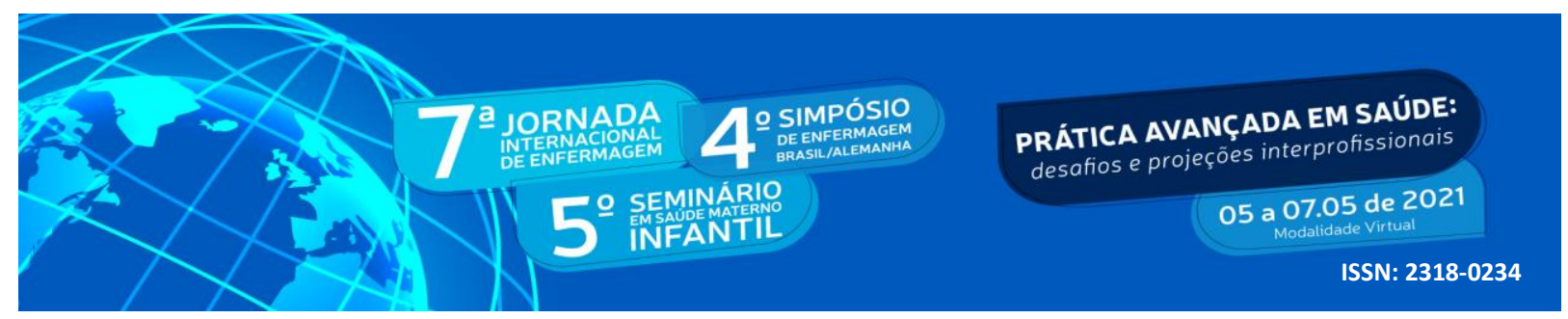

cuidados-materno-infantis-no-sus . Acesso em: 6 mar. 2021.

BRASIL. Ministério da Saúde. Secretaria de Ciência, Tecnologia e Insumos Estratégicos. Departamento de Ciência e Tecnologia. Agenda de Prioridades de Pesquisa do Ministério da Saúde - APPMS [recurso eletrônico]. Brasília: Ministério da Saúde, p. 26, 2018.

GOMES, L. O. S. et al. Práticas dos profissionais de enfermagem diante do parto humanizado. Rev. Enf. UFPE on line, [S.1.], v. 11, n. 6, p. 2576-2585, maio 2017.

MELO, B. E. et al. Implementação das boas práticas na atenção ao parto em maternidade de referência. Rev. Rene, Ceará, v. 18, núm. 3, 2017.

MINAYO, M. C. S. Cientificidade, generalização e divulgação de estudos qualitativos.

Ciência \& Saúde Coletiva, Rio de Janeiro, v.22, n.1, p.16-17, 2017.

NASCIMENTO, E. R. et al . Desafios da assistência de enfermagem ao parto humanizado. Caderno De Graduação - Ciências Biológicas e da Saúde - UNIT - SERGIPE, v. 6, n.1, p. 141-146, 2020.

OPAS. Organização Pan-Americana da Saúde. Objetivos de Desenvolvimento Sustentável. Brasília, DF: OPAS, 2021. Disponível em:

https://www.paho.org/bra/index.php?option=com_content\&view=article\&id=5849:objetivosde-desenvolvimento-sustentavel\&Itemid=875 . Acesso em: 5 mar. 2021.

RIBEIRO, I. A. P. et al. Tecnologias não invasivas de cuidado: percepção das puérperas. Revista de Enfermagem UFPE on line, [S.1.], v. 12, n. 8, p. 2129-2136, ago. 2018.

ROCHA, F. R. et al. Análise da assistência ao binômio mãe-bebê em centro de parto normal. Cogitare Enfermagem, [S.1.], v. 22, n. 2, abr.. 2017.

SANTOS, F. A. P. S. et al . Autonomia do enfermeiro obstetra na assistência ao parto de risco habitual. Rev. Bras. Saude Mater. Infant., Recife, v. 19, n. 2, p. 471-479, jun. 2019.

SILVA, A. L. N. V. et al. Plano de parto: ferramenta para o empoderamento de mulheres durante a assistência de enfermagem. Revista de Enfermagem da UFSM, v. 7, n.1, 144 $151,2017$.

SILVA, C. M. et al . Fatores associados ao contato pele a pele entre mãe/filho e amamentação na sala de parto. Rev. Nutr., Campinas, v. 29, n. 4, p. 457-471, Ago. 2016.

WHO. World Health Organization. Recommendations: intrapartum care for a positive childbirth experience. Geneva: WHO, 2018. 